\title{
Burnout and Metabolic Syndrome in Female Nurses: An Observational Study
}

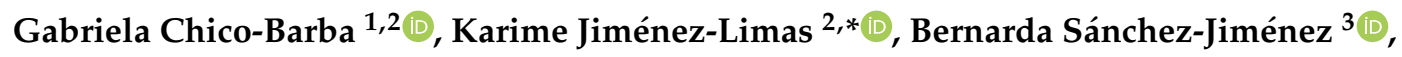 \\ Reyna Sámano ${ }^{1}{ }^{10}$, Ana Lilia Rodríguez-Ventura ${ }^{1}{ }^{(0)}$, Rafael Castillo-Pérez ${ }^{1}$ and \\ Maricruz Tolentino ${ }^{1}$ \\ 1 Departmento de Nutrición y Bioprogramación, Instituto Nacional de Perinatología, Ciudad de México 11000, \\ Mexico; gabyc3@gmail.com (G.C.-B.); ssmr0119@yahoo.com.mx (R.S.); rovalilia@hotmail.com (A.L.R.-V.); \\ armando.castillo1958@gmail.com (R.C.-P.); cruz_tolentino@yahoo.com.mx (M.T.) \\ 2 Escuela de Enfermería, Facultad de Ciencias de la Salud, Universidad Panamericana, \\ Ciudad de México 03920, Mexico \\ 3 Subdirección de Investigación en Intervenciones Comunitarias, Instituto Nacional de Perinatología, \\ Ciudad de México 11000, Mexico; emiberna20@yahoo.com.mx \\ * Correspondence: 0192342@up.edu.mx or kari_jilk@hotmail.com
}

Received: 25 April 2019; Accepted: 28 May 2019; Published: 5 June 2019

\begin{abstract}
Nurses are at risk of having burnout due to workload and job stress—studies have reported that chronic stress is associated with metabolic syndrome. This study aimed to assess the association between burnout and metabolic syndrome in a sample of female nurses. Data were collected from a cross-sectional study from 2016 to 2018 in a tertiary hospital in Mexico City. All nurses that work in the hospital were invited to participate. Information pertaining to sociodemographic (age, education level), work (labor seniority, service area, shift work), anthropometric (weight, waist circumference, blood pressure) and biochemical (glucose, serum lipids) variables were collected. Burnout was assessed using the Maslach Burnout Inventory test, and metabolic syndrome was defined according to the International Diabetes Federation criteria. A total of 168 nurses participated with a median age of 44 years. The prevalence of burnout and metabolic syndrome was $19.6 \%$ and $38.7 \%$, respectively. There was no association between burnout and metabolic syndrome $(p=0.373)$. However, associations of emotional exhaustion (aOR: 14.95; 95\% CI: 1.5-148.7), personal accomplishment (aOR: 0.13; 95\% CI: 0.01-0.99), and night shift (aOR: 12.39; 95\% CI: 1.02-150.5) with increased waist circumference were found. Strategies are needed to prevent burnout and metabolic syndrome in nurses, especially in those who work at night shift.
\end{abstract}

Keywords: nurses; burnout; metabolic syndrome; waist circumference; emotional exhaustion; personal accomplishment; Mexico

\section{Introduction}

Burnout is a syndrome of emotional exhaustion, depersonalization, and low personal accomplishment, which is acquired by workers who have direct contact with customers and users [1]. Among the healthcare professionals, nurses are especially at risk of developing burnout due to the high workload and job stress that is mostly caused by working proximity to patients and taking care of them [2].

Some studies have shown that chronic stress is associated with metabolic syndrome in animal models [3] and clinical settings [4-6], but little is known about the relationship between burnout and metabolic syndrome.

There is evidence that burnout has an impact not only to the emotional status [7] and self-esteem [8] but also on metabolic profile. Cross-sectional studies have shown an association between cardiovascular 
risk factors and burnout $[9,10]$. On the other hand, a longitudinal study found an association between the risk factors for arteriosclerotic disease and the presence of burnout in healthy, middle-aged men [11] — burned out men had significant increases in their waist circumference and body weight at $4-5$ years of follow-up.

The possible pathway between burnout and metabolic syndrome could be explained by the hypothalamic-pituitary-adrenal (HPA) axis. The HPA axis remains hyperactive in the presence of burnout due to exposure to chronic stress, resulting in fat accumulation [12,13]. Body fat mass is a risk factor for cardiometabolic diseases [14,15].

As health professionals, nurses should have good health to take care of the patients and also to be a health promoter, as they are role models, advocates, and educators. Nurses are exposed to different risk factors for non-chronic diseases, for instance, stress and anxiety as a result of their workload and daily interaction with sick people, low physical activity, and long working hours [16-18]. Their job characteristics make it difficult for nurses to have healthy habits, as studies have reported low self-care in nurses [16-18]. There is also a high prevalence of metabolic syndrome [19]. For the reasons mentioned above, the aim of this study was to assess the association between burnout and metabolic syndrome in a sample of female nurses.

\section{Materials and Methods}

\subsection{Study Design}

This observational, cross-sectional study included nurses who work at the Instituto Nacional de Perinatología (National Perinatology Institute, INPer) in Mexico City. Sampling was convenience, non-probabilistic, and based on consecutive cases that met the following inclusion criteria: to be a formal institutional employee, any age, any shift, and area of service. Nursing students, practitioners, and rotating personnel were excluded from the study, as well as pregnant women. Participants were enrolled from 2016 to 2018, with 509 nurses invited to participate, but only 171 (33\%) joined the study. As only three men participated, they have been eliminated from the final sample, in addition to participants with incomplete questionnaires. The total sample consisted of 168 female nurses.

\subsection{Sociodemographic Data and Working Information}

The information regarding age, educational level, socioeconomic status, marital status, working shift, the area of service, labor seniority, having children, and having more than one job was obtained through a questionnaire.

\subsection{Anthropometric Assessment}

The method of measurement was standardized and performed by fixed personnel. Weight was obtained using a digital scale (Tanita Terraillon, $100 \mathrm{~g}$ of precision) and height was assessed using a stadiometer (SECA 231, $0.1 \mathrm{~cm}$ of precision). Body mass index (BMI) was calculated by dividing weight in kilograms by the height in square meters and was categorized according to the World Health Organization cutoff points [20]. Waist circumference was measured using a non-extensible tape (SECA 201, $1 \mathrm{~mm}$ of precision); the participants were asked to stand with their arms raised and abdomen uncovered, the tape was set at the midpoint between the last rib and the iliac crest, and after a normal exhalation, the measurement was taken. Blood pressure was obtained using a mercury sphygmomanometer in the non-dominant arm in the seated position after $5 \mathrm{~min}$ of resting, according to international standards [21]. Two measurements were made and the average was recorded.

\subsection{Biochemical Analyses}

Blood samples were obtained from 7:00 to 8:00 in the morning, after fasting for $12 \mathrm{~h}$. Serum samples were frozen at $-70{ }^{\circ} \mathrm{C}$ until the determination of glucose, glycated hemoglobin $(\mathrm{HbA} 1 \mathrm{c})$, total cholesterol, high-density lipoprotein (HDL) cholesterol, and triglycerides. Participants with an 
$\mathrm{HbA} 1 \mathrm{c}>5.7 \%$ were given an oral glucose tolerance test (OGTT), as this cutoff point is an indicator of increased risk for diabetes, according to the American Diabetes Association guidelines [22]. For the OGTT, an amount of $75 \mathrm{~g}$ of glucose was used, and the reading was taken $2 \mathrm{~h}$ post-test.

\subsection{Burnout Assessment}

Burnout was assessed using the Maslach Burnout Inventory-Human Services Survey test [23]. The questionnaire consists of 22 items, which evaluates three domains: emotional exhaustion (9 items), depersonalization (5 items), and personal accomplishment (8 items). Each item is assessed on a Likert scale, scoring from 0 to 6 . A score was calculated by the sum of points of the items of each domain. Emotional exhaustion and depersonalization have a direct relationship with burnout while, contrarily, personal accomplishment has a negative relation. Even though Maslach proposed to classify each domain as low, mild, or high, it does not give a cutoff point to determine burnout as present or absent. For this study, the total points of each domain were divided into tertiles, and burnout was defined as tertile 3 of emotional exhaustion plus tertile 3 of depersonalization and/or tertile 1 of personal accomplishment, according to Kitaoka-Higashiguchi [11].

\subsection{Metabolic Syndrome Definition}

Metabolic syndrome was defined according to the International Diabetes Federation (IDF) [24]. The criteria are central obesity plus any two of the following: (1) triglycerides $\geq 150 \mathrm{mg} / \mathrm{dL}(1.7 \mathrm{mmol} / \mathrm{L})$ or specific treatment for this lipid abnormality; (2) HDL cholesterol $<50 \mathrm{mg} / \mathrm{dL}(1.29 \mathrm{mmol} / \mathrm{L})$ in females or specific treatment for this lipid abnormality; (3) systolic blood pressure $\geq 130 \mathrm{mmHg}$ or diastolic blood pressure $\geq 85 \mathrm{~mm} \mathrm{Hg}$ or treatment of previously diagnosed hypertension; and (4) fasting plasma glucose $\geq 100 \mathrm{mg} / \mathrm{dL}$ or previously diagnosed type 2 diabetes. Central obesity was defined as waist circumference $\geq 80 \mathrm{~cm}$.

\subsection{Ethics}

The Institutional Review Boards and Ethics Committees from Instituto Nacional de Perinatología (Reg. 212250-3300-11402-01-15) and Facultad de Ciencias de la Salud Universidad Panamericana (Reg. CIEE-001-2017-01) approved the study. Data gathering was confidential, taking into account ethical issues such as autonomy and respect for persons. The guidelines of the Helsinki Declaration were followed. The identification information of the patients was replaced by a folio number, to ensure the confidentiality of the data. All participants received nutritional attention at INPer. If necessary, they also received psychological and medical attention.

\subsection{Statistical Analysis}

We performed a descriptive analysis of the characteristics of the study population. Metabolic syndrome factors were categorized into two categories, according to IDF cutoff points (e.g., triglycerides $\geq 150 \mathrm{mg} / \mathrm{dL}$ ), and frequencies and percentages were calculated for each factor. A Chi-square test was used to determine the association between burnout and metabolic syndrome. Logistic regression models were performed using the metabolic syndrome factors separately as dependent variables and burnout domains in tertiles as independent variables. The reference categories were tertile 1 for emotional exhaustion and depersonalization, and tertile 3 of personal accomplishment. The models were adjusted for sociodemographic, anthropometric and working variables. All statistical analyses were carried out using IBM SPSS Statistics for Windows, Version 20.0 (IBM Corp, Armonk, NY, USA). Statistical significance was considered at $p<0.05$.

\section{Results}

A total of 168 nurses participated in the study. Table 1 shows that the median age of the participants was 44 years. Most of them were married (61.3\%) and had children (74.4\%). The most frequent 
education level was college (37.5\%), followed by technician $(28.6 \%)$. It was found that $60.7 \%$ of the nurses worked in intensive care units. More than half of our sample belonged to the day shift (61.9\%) and had only one job (89.9\%).

Table 1. General characteristics of the total sample of nurses.

\begin{tabular}{|c|c|c|}
\hline Category & Variable & n $(\%)$ \\
\hline \multirow{11}{*}{ Sociodemographics } & Age (years) ${ }^{1}$ & $44(38-50)$ \\
\hline & Marital status & \\
\hline & Single & $65(39)$ \\
\hline & Married & $103(61)$ \\
\hline & Educational level & \\
\hline & Technician & $57(34)$ \\
\hline & College & $63(38)$ \\
\hline & Graduate & $48(28)$ \\
\hline & Having children & \\
\hline & Yes & $125(74)$ \\
\hline & No & $43(26)$ \\
\hline \multirow{14}{*}{ Working related variables } & Labor senority (years) ${ }^{2}$ & $24(16-28)$ \\
\hline & Working years in current service & $4(2-13)$ \\
\hline & Service area & \\
\hline & Intensive care units & $102(61)$ \\
\hline & Inpatients & $20(12)$ \\
\hline & Outpatients & $22(13)$ \\
\hline & No contact with patients & $24(14)$ \\
\hline & Shift work & \\
\hline & Day (8-hour length) & $104(62)$ \\
\hline & Mid-day (7-hour length) & $14(8)$ \\
\hline & Night(12-hour length) & $50(30)$ \\
\hline & More than one job & \\
\hline & Yes & $17(10)$ \\
\hline & No & $151(90)$ \\
\hline
\end{tabular}

${ }^{1}$ Median (P25-P75). ${ }^{2}$ Service area according to the type of patients attended.

The prevalence of burnout and metabolic syndrome in the sample were $19.6 \%$ and $38.7 \%$, respectively. Regarding metabolic syndrome criteria, $82.1 \%$ of the nurses had increased waist circumference (82.1\%), followed by low HDL cholesterol (60.1\%). Only $4.2 \%$ had high blood pressure (Figure 1). 


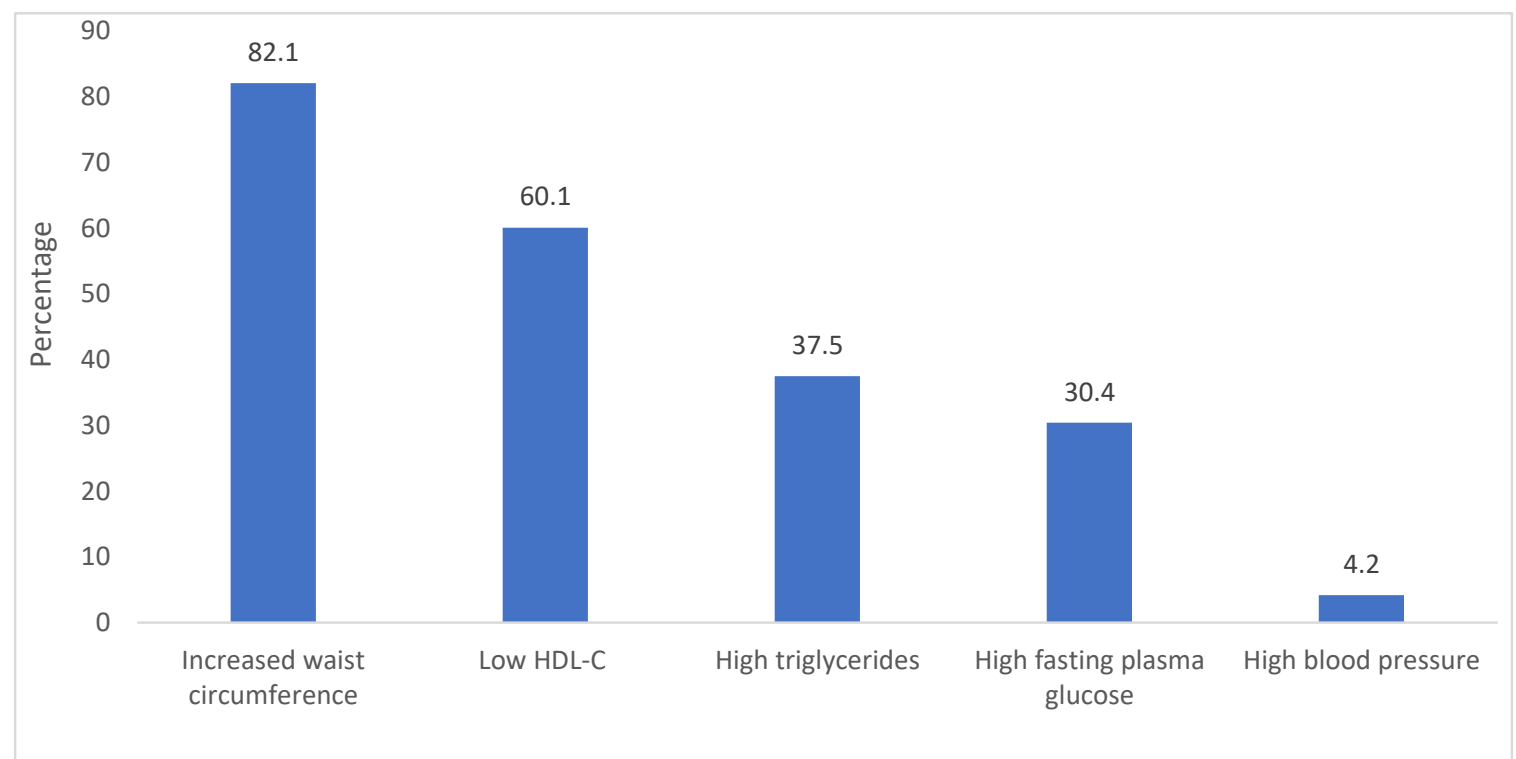

Figure 1. Prevalence of metabolic syndrome criteria in the total sample of nurses. HDL-C: high-density lipoprotein cholesterol.

There was no association between burnout and metabolic syndrome $(p=0.373)$. However, an association between the burnout domains and components of the metabolic syndrome factors was found (Table 2).

Nurses in tertile 2 of emotional exhaustion had a higher risk of having increased waist circumference (adjusted OR: 14.95; 95\% CI: 1.5-148.7; $p=0.021$ ), compared to tertile 1. Contrarily, nurses in tertile 2 of personal accomplishment had a lower risk of having increased waist circumference (aOR: $0.13 ; 95 \% \mathrm{CI}$ : $0.01-0.99 ; p=0.049$ ), compared to tertile 1 . Also, nurses who work in the night shift had a higher risk of having increased waist circumference (aOR: $12.39 ; 95 \%$ CI: $1.02-150.5 ; p=0.048)$. The service area did not show an association with increased waist circumference. There was no association between the burnout domains and the other metabolic syndrome criteria (Table 2). 
Table 2. Association of burnout domains with metabolic syndrome factors.

\begin{tabular}{|c|c|c|c|c|c|c|c|c|c|c|c|c|c|c|c|}
\hline \multirow{2}{*}{$\begin{array}{c}\text { Independent } \\
\text { Variables }\end{array}$} & \multicolumn{3}{|c|}{ Increased Waist Circumference } & \multicolumn{3}{|c|}{ Low HDL-C } & \multicolumn{3}{|c|}{ High Triglycerides } & \multicolumn{3}{|c|}{ High Fasting Plasma Glucose } & \multicolumn{3}{|c|}{ High Blood Pressure } \\
\hline & aOR & $95 \% \mathrm{CI}$ & $p$ & aOR & $95 \% \mathrm{CI}$ & $p$ & aOR & $95 \% \mathrm{CI}$ & $p$ & aOR & $95 \% \mathrm{CI}$ & $p$ & aOR & $95 \% \mathrm{CI}$ & $p$ \\
\hline \multicolumn{16}{|l|}{$\begin{array}{l}\text { Emotional } \\
\text { exhaustion }\end{array}$} \\
\hline $\mathrm{T} 1$ & \multicolumn{3}{|c|}{ Reference } & \multicolumn{3}{|c|}{ Reference } & \multicolumn{3}{|c|}{ Reference } & \multicolumn{3}{|c|}{ Reference } & \multicolumn{3}{|c|}{ Reference } \\
\hline T2 & 14.95 & $1.50-148.71$ & 0.021 & 0.84 & $0.35-2.01$ & 0.710 & 1.26 & $0.53-3.01$ & 0.593 & 0.54 & $0.21-1.38$ & 0.199 & 0.43 & $0.03-5.33$ & 0.513 \\
\hline $\mathrm{T} 3$ & 3.57 & $0.70-18.15$ & 0.125 & 0.66 & $0.28-1.57$ & 0.356 & 1.24 & $0.52-2.95$ & 0.613 & 0.40 & $0.15-1.06$ & 0.067 & 2.35 & $0.25-21.7$ & 0.450 \\
\hline \multicolumn{16}{|c|}{ Depersonalization } \\
\hline $\mathrm{T} 1$ & \multicolumn{3}{|c|}{ Reference } & \multicolumn{3}{|c|}{ Reference } & \multicolumn{3}{|c|}{ Reference } & \multicolumn{3}{|c|}{ Reference } & \multicolumn{3}{|c|}{ Reference } \\
\hline T2 & 4.28 & $0.62-29.65$ & 0.140 & 1.45 & $0.63-3.35$ & 0.380 & 1.17 & $0.51-2.65$ & 0.706 & 1.11 & $0.44-2.76$ & 0.816 & 0.42 & $0.05-3.52$ & 0.425 \\
\hline $\mathrm{T} 3$ & 1.60 & $0.25-10.24$ & 0.615 & 1.10 & $0.47-2.54$ & 0.822 & 0.91 & $0.39-2.14$ & 0.838 & 1.60 & $0.63-4.04$ & 0.316 & 0.23 & $0.01-3.80$ & 0.308 \\
\hline \multicolumn{16}{|l|}{$\begin{array}{c}\text { Personal } \\
\text { accomplishment }\end{array}$} \\
\hline $\mathrm{T} 1$ & 0.26 & $0.03-2.36$ & 0.234 & 1.20 & $0.50-2.84$ & 0.673 & 0.61 & $0.25-1.46$ & 0.271 & 0.80 & $0.30-2.08$ & 0.653 & 0 & 0-0 & 0.997 \\
\hline $\mathrm{T} 2$ & 0.13 & 0.01-0.99 & 0.049 & 0.77 & $0.33-1.80$ & 0.551 & 0.77 & $0.33-1.78$ & 0.546 & 2.10 & $0.86-5.15$ & 0.103 & 1.60 & $0.25-9.98$ & 0.611 \\
\hline $\mathrm{T} 3$ & \multicolumn{3}{|c|}{ Reference } & \multicolumn{3}{|c|}{ Reference } & \multicolumn{3}{|c|}{ Reference } & \multicolumn{3}{|c|}{ Reference } & \multicolumn{3}{|c|}{ Reference } \\
\hline \multicolumn{16}{|l|}{ Shift } \\
\hline Day & \multicolumn{3}{|c|}{ Reference } & \multicolumn{3}{|c|}{ Reference } & \multicolumn{3}{|c|}{ Reference } & \multicolumn{3}{|c|}{ Reference } & \multicolumn{3}{|c|}{ Reference } \\
\hline Mid-day & 13.93 & $0.52-369.9$ & 0.115 & 2.58 & $0.59-11.2$ & 0.206 & 0.61 & $0.13-2.84$ & 0.534 & 1.19 & $0.28-5.09$ & 0.810 & 0.82 & $0.3-18.71$ & 0.904 \\
\hline Night & 12.39 & $1.02-150.5$ & 0.048 & 0.55 & $0.24-1.25$ & 0.156 & 1.08 & $0.47-2.46$ & 0.846 & 0.97 & $0.39-2.38$ & 0.948 & 0.75 & $0.08-6.97$ & 0.805 \\
\hline
\end{tabular}

aOR: adjusted odds ratio, CI: confidence interval, HDL-c: high density lipoprotein cholesterol. Logistic regression models adjusted by age, service area, and body mass index. Bold numbers show statistically significant associations. 


\section{Discussion}

In this sample of Mexican female nurses, the prevalence of burnout (19.6\%) was lower than that reported in other studies. Miranda-Lara et al. found a 33.8\% rate of burnout in a similar sample of Mexican nurses [25]. We have considered different possible explanations for this difference. The first one is that the Maslach Burnout Inventory classifies the level to which the syndrome domains are found (low, mild, or high) but it does not give a cutoff point to determine burnout [23]. The second explanation is that the study performed by Miranda-Lara et al. does not mention the cutoff points used to define the presence of burnout, so the figures cannot be comparable. Finally, more than half of our sample $(66 \%)$ had a high education level—it has been demonstrated in other studies that women with high burnout scores were more likely to have lower education levels [26].

Regarding the metabolic syndrome, the prevalence in our study was lower than the reported for Mexican female adults [27] (38.7\% vs. 52.7\%), but similar when compared to nurses from other countries. In a sample of Brazilian nurses, the prevalence of metabolic syndrome was 38.1\% [9]. Again, we consider the presence of a high education level as a possible explanation, as it has been reported that the lower the education, the higher the frequencies of metabolic syndrome [27,28]. The reason may be because a low education level could cause differences in opportunities for workers to access health services and affect health-related behaviors. In particular, the lower the socioeconomic status of female workers (which usually may depend on education level), the less they care about healthcare and, hence, the higher the risk of metabolic syndrome [28].

When analyzing the metabolic syndrome criteria separately, we found that the prevalence of increased waist circumference in our study $(82.1 \%)$ was close to the $87.8 \%$ reported for Mexican adult women, described in the 2016 Halfway National Health and Nutrition Survey (Ensanut MC 2016) [29]. Moreover, waist circumference was higher in those who worked night shifts. Other studies report similar findings, as working at night is associated with an increased risk of obesity [30], cardiovascular diseases [31], and cancer [32].

On the other hand, the low prevalence of hypertension found in this study (4\%) was surprisingly low compared to the 25.5\% [29] and 32\% reported for the Mexican population and Brazilian nurses, respectively [33]. The reasons behind this low prevalence are still being studied. We consider that the nurses that already had hypertension did not want to participate in the study because they wanted their health information to remain confidential. We came to this assumption after having informal and confidential interviews with some nurses after their participation in the study-they said that they prefer to hide their hypertension diagnosis. There is little evidence regarding this issue. The World Medical Association, in their statement on physician well-being, says that physicians hide their diseases because of denial, confidentiality issues, aversion to the patient role, fear of disciplinary action, and loss of performance-based payment, among others [34]. We believe that the same phenomenon occurs with nurses, as they act as role models in healthcare.

As for the association between burnout domains and metabolic syndrome criteria separately, we found that low emotional exhaustion was associated with increased waist circumference. There is no study that has ever tried to associate these variables. Other articles have related the burnout syndrome with an increase in abdominal adiposity [35], waist circumference, body weight, and BMI [11], but no one has ever reported associations with a specific dimension of burnout. An explanation for this finding is that emotional exhaustion is associated with stress [36,37], and stress increases the risk of metabolic syndrome [4].

Regarding the association of mild personal accomplishment and lower odds of having high waist circumference, other studies reported similar findings by showing that low personal accomplishment was associated with sedentarism in adults [38]. Sedentarism may lead to increased waist circumference and overweight. Another study found that low self-esteem was associated with unhealthy lifestyle (less of 3 days per week and/or less of $30 \mathrm{~min}$ per session of physical activity and poor dietary habits) and, therefore, with increased adiposity [39]. 
Strategies are needed to prevent burnout and metabolic syndrome, and an exercise program may improve both. A previous interventional study explored the impact of an exercise program in banking and insurance workers. The study showed that the workers in the high-intensity exercise program had decreased burnout indicators and their systolic blood pressure was reduced, compared to the control group. In addition, systolic blood pressure was independently associated with burnout and exercise intensity in the crude model, but this was not significant in the adjusted model [40]. Nevertheless, strategies like this should be adapted to nurses' job and lifestyle, especially in those who work at night shift. Another intervention that has shown beneficial effects in health is yoga, with evidence from randomized control trials and systematic reviews showing that yoga reduced burnout, specifically emotional exhaustion and depersonalization [41,42], and improved cardiometabolic parameters, like fasting blood glucose, triglycerides, and blood pressure [43-45].

Regarding the pathway between burnout and metabolic syndrome, future studies should adequately assess biomarkers involved in the activation of the HPA axis, like serum cortisol. Even though cortisol levels increase when the HPA axis is activated in chronic stress [12], there is inconsistent evidence about the levels of cortisol and burnout. The evidence from different systematic reviews and meta-analysis showed that the comparability of the studies is limited due to poor quality assessments of cortisol and burnout [46,47].

One of the strengths of this study is that, to our knowledge, it is one of the few studies that assess the association of burnout and metabolic syndrome. Also, for the assessment of burnout, we used the Maslach Burnout Inventory, which continues to be the most widely used instrument and is considered to be the gold standard. Moreover, we had a high percentage of participation (33\%) from nurses, since a $15 \%$ participation has been reported in other studies [40]. However, it is likely that non-participants may have had pre-existing cardiovascular diseases and, thus, did not wish to participate in the study. Another possible reason for not participating is that often the number of nurses in each service is inadequate, so they cannot leave their service to participate in our study assessments.

The sample size is one of the limitations of our study, as it is likely that a greater sample size would result in narrower confidence intervals and burnout domains to be associated with other metabolic syndrome criteria. Also, our sample is not representative of all Mexican nurses as it consists only of female nurses of a tertiary hospital. Regarding the cross-sectional design, we cannot assume causality in the associations that we found.

\section{Conclusions}

Amongst female nurses working in a tertiary hospital, there was no association between burnout and metabolic syndrome. Nevertheless, nurses in tertile 2 of emotional exhaustion had a higher risk of having increased waist circumference, and nurses in tertile 2 of personal accomplishment had a lower risk of having increased waist circumference. Strategies are needed to prevent burnout and metabolic syndrome in female nurses, especially in those who work at night shift.

Author Contributions: Conceptualization: B.S.-J., G.C.-B., and K.J.-L.; formal analysis: G.C.-B., and K.J.-L.; funding acquisition: B.S.-J., and A.L.R.-V.; investigation: B.S.-J., K.J.-L., R.S., M.T., R.C.-P., and A.L.R.-V.; methodology: K.J.-L., B.S.-J., A.L.R.-V., M.T., R.C.-P., and R.S.; project administration: G.C.-B.; supervision: G.C.-B.; writing_original draft: K.J.-L., and G.C.-B.; writing—review and editing: K.J.-L., G.C.-B., B.S.-J., and R.S.

Funding: This research was funded by Instituto Nacional de Perinatología, grant number 212250-3300-11402-01-15.

Acknowledgments: We thank Natalie Ávila-González, Antonio Villa and Ximena Rubilar for their contribution to this research.

Conflicts of Interest: The authors declare no conflict of interest. 


\section{References}

1. Maslach, C.; Jackson, S.; Leiter, M. Maslach Burnout Inventory, 3rd ed.; Consulting Psychologists Press: Palo Alto, CA, USA, 1996.

2. Gómez-Urquiza, J.L.; De la Fuente-Solana, E.I.; Albendín-García, L. Prevalence of Burnout Syndrome in Emergency Nurses: A Meta-Analysis. Crit. Care Nurse 2017, 37, e1-e9. [CrossRef] [PubMed]

3. Branyan, K.W.; Devallance, E.R.; Lemaster, K.A.; Skinner, R.C.; Bryner, R.W.; Olfert, I.M.; Kelley, E.E.; Frisbee, J.C.; Chantler, P.D. Role of Chronic Stress and Exercise on Microvascular Function in Metabolic Syndrome. Med. Sci. Sports Exerc. 2018, 50, 957-966. [CrossRef] [PubMed]

4. Ortiz, M.S.; Sapunar, J. Longitudinal association between chronic psychological stress and metabolic syndrome. Rev. Med. Chile 2018, 146, 1278-1285. [CrossRef] [PubMed]

5. Chandola, T.; Brunner, E.; Marmot, M. Chronic stress at work and the metabolic syndrome: Prospective study. Br. Med. J. 2006, 332, 521-525. [CrossRef] [PubMed]

6. Bergmann, N.; Ballegaard, S.; Krogh, J.; Bech, P.; Hjalmarson, Å.; Gyntelberg, F.; Faber, J. Chronic psychological stress seems associated with elements of the metabolic syndrome in patients with ischaemic heart disease. Scand. J. Clin. Lab. Investig. 2017, 77, 513-519. [CrossRef] [PubMed]

7. Sánchez-Jiménez, B.; Flores-Ramos, M.; Sámano, R.; Rodíguez-Ventura, A.L.; Chinchilla Ochoa, D. Factores relacionados a la presencia del síndrome de burnout en una muestra de enfermeras del sector salud, Ciudad de México. Rev. Salud Pública y Nutr. 2018, 17, 1-8.

8. Chakraborty, R.; Chatterjee, A.; Chaudhury, S. Internal predictors of burnout in psychiatric nurses: An Indian study. Ind. Psychiatry J. 2012, 21, 119-124. [PubMed]

9. Ribeiro, P.R.; Marziale, H.M.P.; Martins, J.T.; Ribeiro, P.H.V.; Robazzi, M.L.D.C.C.; Dalmas, J.C. Prevalence of Metabolic Syndrome among nursing personnel and its association with occupational stress, anxiety and depression. Rev. Lat.-Am. Enferm. 2015, 23, 435-440. [CrossRef] [PubMed]

10. Das Merces, M.C.; Gomes, A.M.T.; Guimarães, E.L.P.; Santana, A.I.C.; De Souza e Silva, D.; Machado, Y.Y.; Couto, P.L.S.; França, L.C.M.; De Figueiredo, V.P.; D’Oliveira Júnior, A. Burnout and metabolic conditions are professionals of nursing: A pilot study. Enfermagem Brasil. 2018, 17, 90-98. [CrossRef]

11. Kitaoka-Higashiguchi, K.; Morikawa, Y.; Miura, K.; Sakurai, M.; Ishizaki, M.; Kido, T.; Naruse, Y.; Nakagawa, H. Burnout and risk factors for arteriosclerotic disease: Follow-up study. J. Occup. Health 2009, 51, 123-131. [CrossRef]

12. Melamed, S.; Shirom, A.; Toker, S.; Berliner, S.; Shapira, I. Burnout and risk of cardiovascular disease: Evidence, possible causal paths, and promising research directions. Psychol. Bull. 2006, 132, 327-353. [CrossRef] [PubMed]

13. Brunner, E.; Marmot, M. Social organization, stress, and health. In Social Determinants of Health; Marmot, M., Wilkinson, R., Eds.; Oxford University Press: New York, NY, USA, 2006; pp. 6-30.

14. Bastien, M.; Poirier, P.; Lemieux, I.; Després, J.P. Overview of epidemiology and contribution of obesity to cardiovascular disease. Prog. Cardiovasc. Dis. 2014, 56, 369-381. [CrossRef] [PubMed]

15. Ortega-Loubon, C.; Fernández-Molina, M.; Singh, G.; Correa, R. Obesity and its cardiovascular effects. Diabetes Metab. Res. Rev. 2019, 35, e3135. [CrossRef] [PubMed]

16. Priano, S.; Hong, O.; Chen, J. Lifestyles and Health-Related Outcomes of U.S. Hospital Nurses: A Systematic Review. Nurs. Outlook 2018, 66, 66-76. [CrossRef] [PubMed]

17. Blake, H.; Stanulewicz, N.; Griffiths, K. Healthy Lifestyle Behaviors and Health Promotion Attitudes in Preregistered Nurses: A Questionnaire Study. J. Nurs. Educ. 2017, 56, 94-103. [CrossRef] [PubMed]

18. Mustafaei Najaf-Abadi, H.; Rezaei, B. Health-promoting behaviours of Iranian nurses and its relationship with some occupational factors: A cross sectional study. J. Nurs. Manag. 2018, 26, 717-725. [CrossRef] [PubMed]

19. Shin, D.; Kongpakpaisarn, K.; Bohra, C. Trends in the prevalence of metabolic syndrome and its components in the United States 2007-2014. Int. J. Cardiol. 2018, 259, 216-219. [CrossRef] [PubMed]

20. World Health Organization. Obesity and Overweight. Fact Sheets. Available online: https://www.who.int/ news-room/fact-sheets/detail/obesity-and-overweight (accessed on 20 April 2019).

21. Pickering, T.G.; Hall, J.E.; Appel, L.J.; Falkner, B.E.; Graves, J.; Hill, M.N.; Jones, D.W.; Kurtz, T.; Sheps, S.G.; Roccella, E.J. Recommendations for Blood Pressure Measurement in Humans and Experimental Animals. Hypertension 2004, 45, 142-161. [CrossRef] 
22. American Diabetes Association. Classification and Diagnosis of Diabetes: Standards of Medical Care in Diabetes-2019. Diabetes Care 2019, 42, S13-S28. [CrossRef]

23. Maslach, C.; Leiter, M.P.; Schaufeli, W. Measuring Burnout. In The Oxford Handbook of Organizational Well Being; Cartwright, S., Cooper, C.L., Eds.; Oxford University Press: Oxford, UK, 2008; pp. 86-108. ISBN 9780199211913.

24. International Diabetes Federation. IDF Diabetes Atlas, 8th ed.; International Diabetes Federation: Brussels, Belgium, 2017; ISBN 9782930229874.

25. Miranda-Lara, V.R.; Monzalvo-Herrera, G.; Hernández-Caballero, B.; Ocampo-Torres, M. Prevalence of burnout syndrome in nursing staff of two health institutions. Rev. Enferm Inst. Mex. Seguro Soc. 2016, 24, 115-122.

26. Soares, J.J.F.; Grossi, G.; Sundin, Ö. Burnout among women: Associations with demographic/socio-economic, work, life-style and health factors. Arch. Women's Ment. Health 2007, 10, 61-71. [CrossRef]

27. Rojas, R.; Aguilar-Salinas, C.A.; Jiménez-Corona, A.; Shamah-Levy, T.; Rauda, J.; Ávila-Burgos, L.; Villalpando, S.; Lazcano Ponce, E. Metabolic syndrome in Mexican adults. Results from the National Health and Nutrition Survey 2006. Salud Publica Mex. 2010, 52, s11-s18. [CrossRef]

28. Cho, D.Y.; Koo, J.W. Differences in metabolic syndrome prevalence by employment type and sex. Int. J. Environ. Res. Public Health 2018, 15, 1798. [CrossRef]

29. Secretaría de Salud. Encuesta Nacional de Salud y Nutrición de Medio Camino 2016; Instituto Nacional de Salud Pública: Cuernavaca, Mexico, 2016.

30. Saulle, R.; Bernardi, M.; Chiarini, M.; Backhaus, I.; La Torre, G. Shift work, overweight and obesity in health professionals: A systematic review and meta-analysis. Clin. Ter. 2018, 169, e189-e197.

31. Peplonska, B.; Bukowska, A.; Sobala, W. Association of rotating night shift work with BMI and abdominal obesity among nurses and midwives. PLoS ONE 2015, 10, e0133761. [CrossRef]

32. Straif, K.; Baan, R.; Grosse, Y.; El Ghissassi, F.; Altieri, A.; Cogliano, V.; Group, W. Carcinogenicity of shift-work, painting, and fire-fighting. Lancet Oncol. 2007, 8, 1065-1066. [CrossRef]

33. Urbanetto, J.D.S.; Prado Lima Figuereido, A.E.; da Silva Gustavo, A.; Bosi de Souza Magnago, T.S.; Pinheiro da Costa, B.E.; Poli-de-Figueiredo, C.E. Arterial hypertension in nursing personnel of an emergency hospital. Int. J. Nurs. Pract. 2015, 21, 433-442. [CrossRef]

34. World Medical Association General Assembly. WMA Statement on Physicians Well-being. In Proceedings of the 66th WMA General Assembly, Moscow, Russia, 14-17 October 2015.

35. das Merces, M.C.; de Souza e Silva, D.; Lua, I.; Oliveira, D.S.; de Souza, M.C.; Júnior, A.D.O. Burnout syndrome and abdominal adiposity among Primary Health Care nursing professionals. Psicol. Reflexão E Crítica 2016, 29, 44. [CrossRef]

36. Halm, M.; Peterson, M.; Kandels, M.; Sabo, J.; Blalock, M.; Braden, R.; Gryczman, A.; Krisko-Hagel, K.; Larson, D.; Lemay, D.; et al. Hospital nurse staffing and patient mortality, emotional exhaustion, and job dissatisfaction. Clin. Nurse Spec. 2005, 19, 241-251. [CrossRef]

37. Friganović, A.; Selič, P.; Ilić, B.; Sedić, B. Stress and burnout syndrome and their associations with coping and job satisfaction in critical care nurses: A literature review. Psychiatr. Danub. 2019, 31, 21-31.

38. Agüero, S.D.; Sánchez, H.; Valladares, M.; López, A.; Badilla, P.V.; Herrera, T. Physical activity and style profile of life health promoters in older Chilean adults. Rev. Med. Chile 2017, 145, 1535-1540.

39. Sánchez-Jiménez, B.; Sámano, R.; Chinchilla-Ochoa, D.; Morales-Hernández, R.; Rodríguez-Ventura, A. Demographics and psychological factors associated with adiposity in nurses. Int. J. Environ. Res. Public Health 2018, 15, 634. [CrossRef]

40. Tsai, H.H.; Yeh, C.Y.; Su, C.T.; Chen, C.J.; Peng, S.M.; Chen, R.Y. The Effects of Exercise Program on Burnout and Metabolic Syndrome Components in Banking and Insurance Workers. Ind. Health 2013, 51, 336-346. [CrossRef]

41. Alexander, G.K.; Rollins, K.; Walker, D.; Wong, L.; Pennings, J. Yoga for Self-Care and Burnout Prevention among Nurses. Workplace Health Saf. 2015, 63, 462-470. [CrossRef]

42. Cocchiara, R.; Peruzzo, M.; Mannocci, A.; Ottolenghi, L.; Villari, P.; Polimeni, A.; Guerra, F.; La Torre, G. The Use of Yoga to Manage Stress and Burnout in Healthcare Workers: A Systematic Review. J. Clin. Med. 2019, 8, 284. [CrossRef]

43. Cramer, H.; Lauche, R.; Haller, H.; Steckhan, N.; Michalsen, A.; Dobos, G. Effects of yoga on cardiovascular disease risk factors: A systematic review and meta-analysis. Int. J. Cardiol. 2014, 173, 170-183. [CrossRef] 
44. Cramer, H.; Langhorst, J.; Dobos, G.; Lauche, R. Yoga for metabolic syndrome: A systematic review and meta-analysis. Eur. J. Prev. Cardiol. 2016, 23, 1982-1993. [CrossRef]

45. Chu, P.; Gotink, R.A.; Yeh, G.Y.; Goldie, S.J.; Hunink, M.G.M. The effectiveness of yoga in modifying risk factors for cardiovascular disease and metabolic syndrome: A systematic review and meta-analysis of randomized controlled trials. Eur. J. Prev. Cardiol. 2016, 23, 291-307. [CrossRef]

46. Danhof-Pont, M.B.; van Veen, T.; Zitman, F.G. Biomarkers in burnout: A systematic review. J. Psychosom. Res. 2011, 70, 505-524. [CrossRef]

47. Cadegiani, F.A.; Kater, C.E. Adrenal fatigue does not exist: A systematic review. BMC Endocr. Disord. 2016, 16,48 .

(C) 2019 by the authors. Licensee MDPI, Basel, Switzerland. This article is an open access article distributed under the terms and conditions of the Creative Commons Attribution (CC BY) license (http://creativecommons.org/licenses/by/4.0/). 